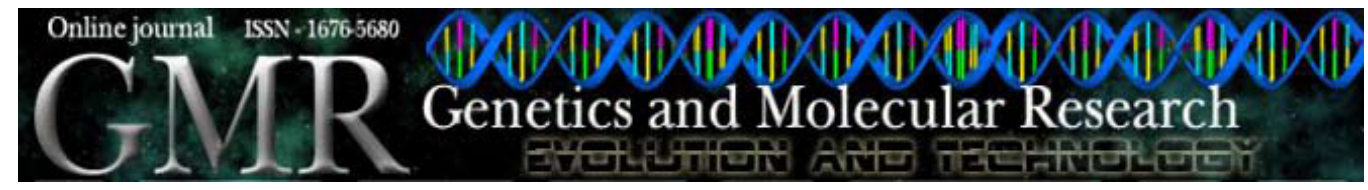

\title{
Performance of human immunostimulating agents in the improvement of fish cytogenetic preparations
}

\author{
W.F. Molina ${ }^{1}$, D.E.O. Alves ${ }^{1}$, W.C. Araújo ${ }^{1}$, P.A. Martinez ${ }^{1}$, M.F.M. Silva ${ }^{2}$ \\ and G.W.W.F. Costa ${ }^{1}$ \\ 'Departamento de Biologia Celular e Genética, Centro de Biociências, \\ Universidade Federal do Rio Grande do Norte, Natal, RN, Brasil \\ ${ }^{2}$ DNOCS/Estação de Piscicultura Estevão de Oliveira, Caicó, RN, Brasil \\ Corresponding author: W.F. Molina \\ E-mail: molinawf@pq.cnpq.br
}

Genet. Mol. Res. 9 (3): 1807-1814 (2010)

Received April 20, 2010

Accepted June 18, 2010

Published September 14, 2010

DOI 10.4238/vol9-3gmr840

\begin{abstract}
Inoculation with bacterial or fungal antigens that stimulate cell proliferation has been widely used to obtain metaphases for cytogenetic studies of fish. We evaluated the potential of new pharmaceutical compounds as mitogenic agents in fish, testing the efficacy of Aminovac ${ }^{\circledR}$ (mixed antigens and epsilon-acetamidocaproic acid), Broncho-Vaxom ${ }^{\circledR}$ (bacterial lysate) and Estimoral ${ }^{\circledR}$ (bacterial lysate) to increase the mitotic index in fingerlings of the Neotropical fish Prochilodus brevis (Prochilodontidae) and Hoplias malabaricus (Erythrinidae), which were obtained from an aquaculture facility. The animals were treated with intramuscular or intraperitoneal injections of $1 \mathrm{~mL} / 50 \mathrm{~g}$ body weight of each compound. After $24 \mathrm{~h}$, cytogenetic analyses were performed. All immunostimulants tested significantly stimulated cell division, although Aminovac ${ }^{\circledR}$ proved to be the most efficient, leading to a 5-fold increase in the number of metaphase cells compared to the control group and to a 2-fold increase compared
\end{abstract}


to conventional yeast inoculation. This compound facilitates fish cytogenetics analyses as it stimulates the proliferation of defense cells and reduces loss of samples. It will be especially useful for the study of specimens that either have a high commercial value or are fragile, small and/or rare.

Key words: Fish cytogenetics; Mitotic stimulation; Broncho-Vaxom; Estimoral; Aminovac

\section{INTRODUCTION}

Knowledge about cytogenetic aspects in fish has been useful in understanding evolutionary, genomic and taxonomic features of this group, and it has also provided a database for conservation policies (Molina, 2007; Oliveira et al., 2007; Ráb et al., 2007). Advances in banding techniques and chromosomal mapping, however, are invariably dependent on the number and quality of metaphase spreads.

The mitotic index in healthy fish specimens is usually low, especially during certain seasons and ontogenetic stages. The biological peculiarities of some species, such as body length, fragility as a result of transportation and captivity and area of occurrence, can hinder the acquisition of chromosomes from cell culture. In these cases, mitotic stimulants should be used in direct chromosomal preparations.

The technique of mitotic stimulation in vertebrates relies on the immunological response to antigens, which can be obtained from a wide variety of sources: live microorganisms such as yeasts (Lee and Elder, 1980; Lozano et al., 1988); biological compounds such as horse serum (Ojima and Kurishita, 1980) and phytohemagglutinin, a lectin found in plants able to induce mitosis (Baruffaldi et al., 1992; Takai and Ojima, 1995); natural or induced infection with parasites such as Ichthiophirium multifilis (Moreira-Filho and Bertollo, 1991) and parasitic mollusk larvae (Woznicki et al., 2004), and chemical agents such as phenylhydrazine (Cucchi and Baruffaldi, 1989) and cobalt chloride (Cucchi and Baruffaldi, 1990; Woznicki et al. 2004). All these methods trigger, to different degrees, the proliferation of defense cells, which is macroscopically characterized by an enlarged kidney, the hematopoietic organ in fish (Kunz, 2004).

Taking advantage of this immune response to external agents, cytogenetic study protocols were developed for fish that involved their inoculation with antigenic substances and analyses of kidney cells. The application of a glucose solution containing the yeast Saccharomyces cerevisae (Lee and Elder, 1980; Lozano et al., 1988; Park et al., 2005) is the most widely used method because it is efficient, easy and cost-saving. Although resulting in a high number of mitotic kidney cells, this method has the disadvantage of causing a remarkable increase in mortality rate (Molina, 2001) as a result of either external injuries or internal organ failure due to either general toxicity or a pressure increase that occurs due to gas production. Such a disadvantage is particularly restrictive in studies that involve fragile, unhealthy or very small animals. To mitigate this type of damage, the bacterial and fungal lysates have been used as a successful alternative for the stimulation of cell division in fish (Molina, 2001). Nonetheless, an evaluation of the performance of different immunostimulants to optimize chromosomal preparation in fish is still necessary. The goals of the present study were both to test the 
efficacy of new commercial compounds capable of inducing mitotic division in fish and to standardize their utilization, using the freshwater Neotropical species Prochilodus brevis and Hoplias malabaricus as models.

\section{MATERIAL AND METHODS}

The mitotic induction experiment was performed using 22 P. brevis (Steindachner, $1875)$ specimens of the same age and weight ( $100 \mathrm{~g})$ and six H. malabaricus (Bloch, 1794) specimens of the same weight $(\sim 20 \mathrm{~g})$ from the aquaculture facility Estevão de Oliveira in the Department of Actions Against Drought (DNOCS), Caicó, State of Rio Grande do Norte, Brazil. Each group received, either via intramuscular or intraperitoneal injection, a solution of each immunostimulating compound: Aminovac ${ }^{\circledR}$, a human oral desensitizer composed of mixed protein antigens from food, inhalational substances and microorganisms of the respiratory system associated with epsilon-acetamidocaproic acid; Broncho-Vaxom ${ }^{\circledR}$, a lyophilized bacterial lysate composed of strains of Haemophilus influenzae, Diplococcus pneumoniae, Klebsiella pneumoniae, K. ozaenae, Staphylococcus aureus, Streptococcus pyogenes, S. viridians, and Moraxella catarrhalis (Neisseria); Estimoral ${ }^{\mathbb{Q}}$, a bacterial lysate mainly composed of strains of H. influenzae, K. pneumoniae, S. aureus, S. pyogenes, S. mitis, S. pneumoniae, Branhamella catarrhalis, and others, and a glucose solution of Saccharomyces cerevisae. All compounds were injected at a proportion of $1 \mathrm{~mL} / 50 \mathrm{~g}$ body weight. The animals were divided into six treatment groups, including the control group, without mitotic stimulation (NS), and groups inoculated with non-treated water (T1), $0.1 \mathrm{mg} / \mathrm{mL}$ Aminovac ${ }^{\circledR}$ in deionized water (T2), $0.7 \mathrm{mg} /$ $\mathrm{mL}$ Broncho-Vaxom ${ }^{\circledR}$ in deionized water (T3), $0.6 \mathrm{mg} / \mathrm{mL}$ Estimoral ${ }^{\circledR}$ in deionized water (T4), or a $0.25 \mathrm{~g} / \mathrm{mL}$ sucrose solution of $S$. cerevisae $(6 \mathrm{~g}$ yeast, $6 \mathrm{~g}$ sucrose, $25 \mathrm{~mL}$ deionized water; stored at $37^{\circ} \mathrm{C}$ for $20-30 \mathrm{~min}$ ) (T5). Each group comprised three to four specimens of $P$. brevis and one specimen of $H$. malabaricus.

After a 24-h treatment period, the animals were anesthetized using clove oil, sacrificed as described by Henyey et al. (2002), and fragments of the anterior kidney were removed. The acquisition of mitotic chromosomes was performed as described by Gold et al. (1990). After extraction and fixation of the tissue, three drops of the cell suspension were applied onto glass slides covered with a film of water at $60^{\circ} \mathrm{C}$, followed by air-drying. The slides were then stained with a 5\% Giemsa solution in phosphate buffer, $\mathrm{pH} 6.8$, for 10 min. The mean number of metaphases for each specimen was based on analyses of three slides per individual. The metaphase spreads were analyzed using $1000 \mathrm{X}$ magnification, and they were photographed using an optic microscope (Olympus BX50) that was equipped with a high-resolution digital system. The efficacy (E) of the antigens tested was defined by the ratio of the absolute frequency of mitotic metaphases for each treatment to the number of metaphases obtained in the control treatment (NS) within samples from both fish species.

One-way analysis of variance was performed using the Biostatistics for Windows software to determine significant differences between control and treated groups. A probability level of $\mathrm{P}<0.05$ was considered to be significant.

\section{RESULTS}

The mean number of mitotic metaphases was 1.39 metaphase/slide for NS $(E=1.00)$, 
1.87 for $\mathrm{T} 1(\mathrm{E}=3.11), 8.26$ for $\mathrm{T} 2(\mathrm{E}=12.22), 6.91$ for $\mathrm{T} 3(\mathrm{E}=9.22), 4.86$ for $\mathrm{T} 4(\mathrm{E}=7.44)$, and 5.75 for T5 $(\mathrm{E}=5.77)$ (Table 1). Although a significant increase in the number of metaphases

\begin{tabular}{|c|c|c|c|c|c|c|c|}
\hline \multirow[t]{2}{*}{ Treatment } & \multirow[t]{2}{*}{ Specimen } & \multirow[t]{2}{*}{ Species } & \multirow[t]{2}{*}{ Antigen } & \multicolumn{3}{|c|}{ Slides } & \multirow[t]{2}{*}{ Total/slide } \\
\hline & & & & I & II & $\overline{\mathrm{III}}$ & \\
\hline NS & 2597 & P. brevis & \multirow[t]{7}{*}{ No stimulation } & 2 & 2 & 0 & 4 \\
\hline NS & 2601 & P. brevis & & 0 & 0 & 0 & 0 \\
\hline NS & 2603 & P. brevis & & 0 & 1 & 0 & 1 \\
\hline \multirow[t]{4}{*}{ NS } & 2808 & H. malabaricus & & 3 & 0 & 1 & 4 \\
\hline & & & & \multicolumn{3}{|l|}{ Total } & 9 \\
\hline & & & & \multicolumn{3}{|l|}{ Average/slide } & 2.25 \\
\hline & & & & \multicolumn{3}{|l|}{ Efficacy } & 1.00 \\
\hline $\mathrm{T} 1$ & 2634 & P. brevis & Water & 1 & 2 & 1 & 4 \\
\hline $\mathrm{T} 1$ & 2635 & P. brevis & & 1 & 2 & 3 & 6 \\
\hline $\mathrm{T} 1$ & 2677 & P. brevis & & 2 & 2 & 4 & 8 \\
\hline \multirow[t]{4}{*}{$\mathrm{T} 1$} & 2810 & H. malabaricus & & 3 & 5 & 2 & 10 \\
\hline & & & & \multicolumn{3}{|l|}{ Total } & 28 \\
\hline & & & & \multicolumn{3}{|l|}{ Average/slide } & 7.00 \\
\hline & & & & \multicolumn{3}{|l|}{ Efficacy } & 3.11 \\
\hline $\mathrm{T} 2$ & 2819 & P. brevis & Aminovac & 5 & 8 & 4 & 17 \\
\hline $\mathrm{T} 2$ & 2820 & P. brevis & & 3 & 5 & 5 & 13 \\
\hline $\mathrm{T} 2$ & 2631 & P. brevis & & 24 & 13 & 15 & 52 \\
\hline \multirow[t]{4}{*}{$\mathrm{T} 2$} & 2805 & H. malabaricus & & 6 & 14 & 8 & 28 \\
\hline & & & & \multicolumn{3}{|l|}{ Total } & 110 \\
\hline & & & & \multicolumn{3}{|l|}{ Average/slide } & 27.50 \\
\hline & & & & \multicolumn{3}{|l|}{ Efficacy } & 12.22 \\
\hline T3 & 2623 & P. brevis & Broncho-Vaxom & 4 & 5 & 4 & 13 \\
\hline T3 & 2624 & P. brevis & & 10 & 5 & 4 & 19 \\
\hline $\mathrm{T} 3$ & 2625 & P. brevis & & 13 & 5 & 9 & 27 \\
\hline \multirow[t]{4}{*}{ T3 } & 2809 & H. malabaricus & & 8 & 6 & 10 & 24 \\
\hline & & & & \multicolumn{3}{|l|}{ Total } & 83 \\
\hline & & & & \multicolumn{3}{|l|}{ Average/slide } & 20.75 \\
\hline & & & & \multicolumn{3}{|l|}{ Efficacy } & 9.22 \\
\hline $\mathrm{T} 4$ & 2633 & P. brevis & Estimoral & 11 & 5 & 8 & 24 \\
\hline T4 & 2636 & P. brevis & & 3 & 2 & 3 & 8 \\
\hline $\mathrm{T} 4$ & 2678 & P. brevis & & 3 & 4 & 4 & 11 \\
\hline $\mathrm{T} 4$ & 2807 & H. malabaricus & & 7 & 13 & 4 & 24 \\
\hline & & & & Total & & & 67 \\
\hline & & & & Average/slide & & & 16.75 \\
\hline & & & & Efficacy & & & 7.44 \\
\hline T5 & 2679 & P. brevis & S. cerevisae & 3 & 5 & 6 & $14^{1.44}$ \\
\hline T5 & 2730 & P. brevis & & 6 & 7 & 6 & 19 \\
\hline T5 & Death & P. brevis $\dagger$ & & - & - & - & - \\
\hline T5 & 2806 & H. malabaricus & & 11 & 3 & 5 & 19 \\
\hline & & & & Total & & & 52 \\
\hline & & & & Average/slide & & & 17.33 \\
\hline & & & & Efficacy & & & 5.77 \\
\hline
\end{tabular}

$\mathrm{NS}=$ without mitotic stimulations (control group); $\mathrm{T} 1=$ inoculated with non-treated water; $\mathrm{T} 2=0.1 \mathrm{mg} / \mathrm{mL}$ Aminovac in deionized water; $\mathrm{T} 3=0.7 \mathrm{mg} / \mathrm{mL}$ Broncho-Vaxom in deionized water; $\mathrm{T} 4=0.6 \mathrm{mg} / \mathrm{mL}$ Estimoral in deionized water; $\mathrm{T} 5=$ a $0.25 \mathrm{mg} / \mathrm{mL}$ sucrose solution $+6 \mathrm{~g}$ Saccharomyces cerevisae.

was observed after inoculation with non-treated water $(\mathrm{T} 1 ; \mathrm{P}<0.05)$, the absolute number of metaphases was still low. The efficacy of each treatment was estimated relative to the number of metaphases seen in the control group, which represented the basal level of dividing cells in the animals (Figures 1 and 2). There was only a single death that occurred in the T5 group. Statistical analyses showed significant differences for all treatments when compared to the non-treated control group $(\mathrm{P}<0.001)$. 


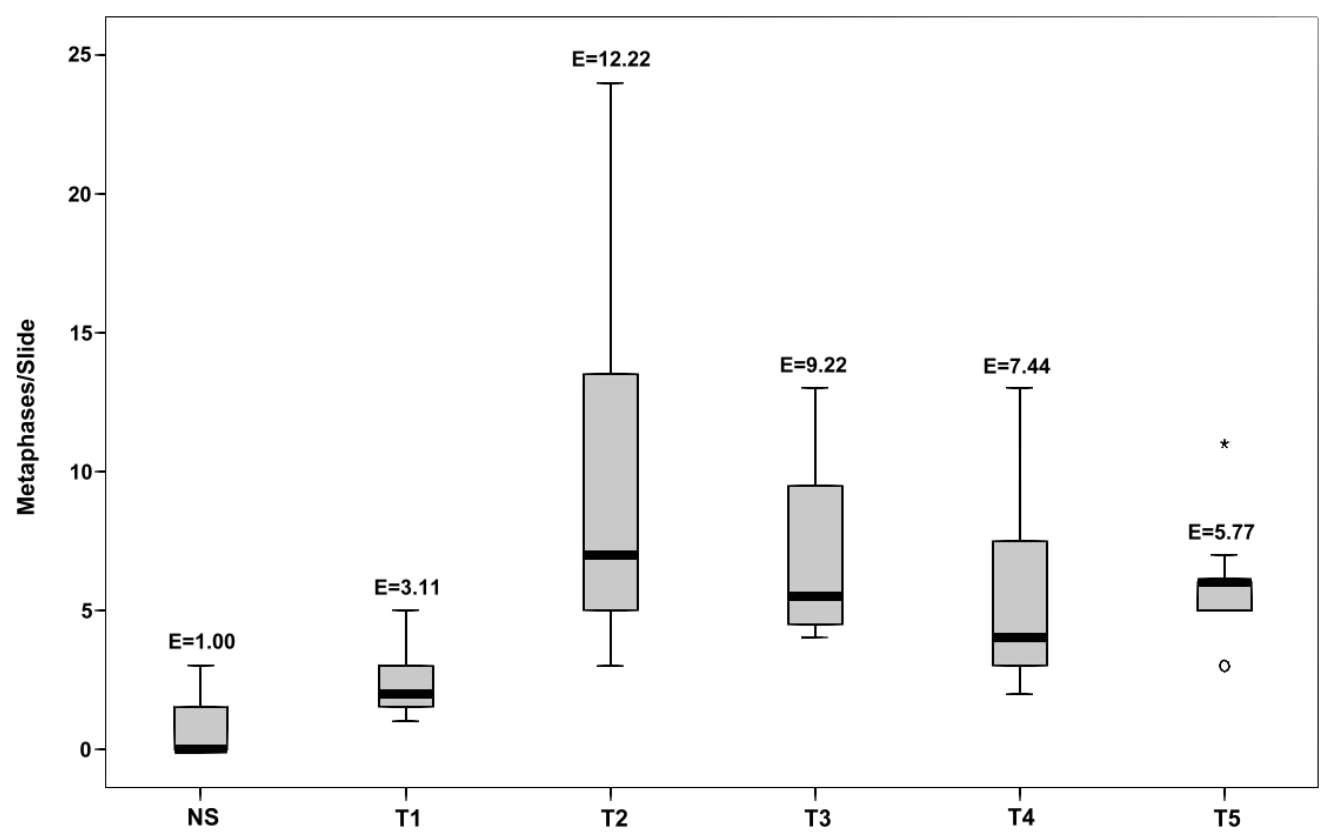

Figure 1. Box plot of the frequency of metaphases after induction of cell division using distinct immunostimulants. Efficacy (E) is indicated for each treatment. Outlying value is indicated by a small circle, and a far outlying value is indicated by an asterisk.

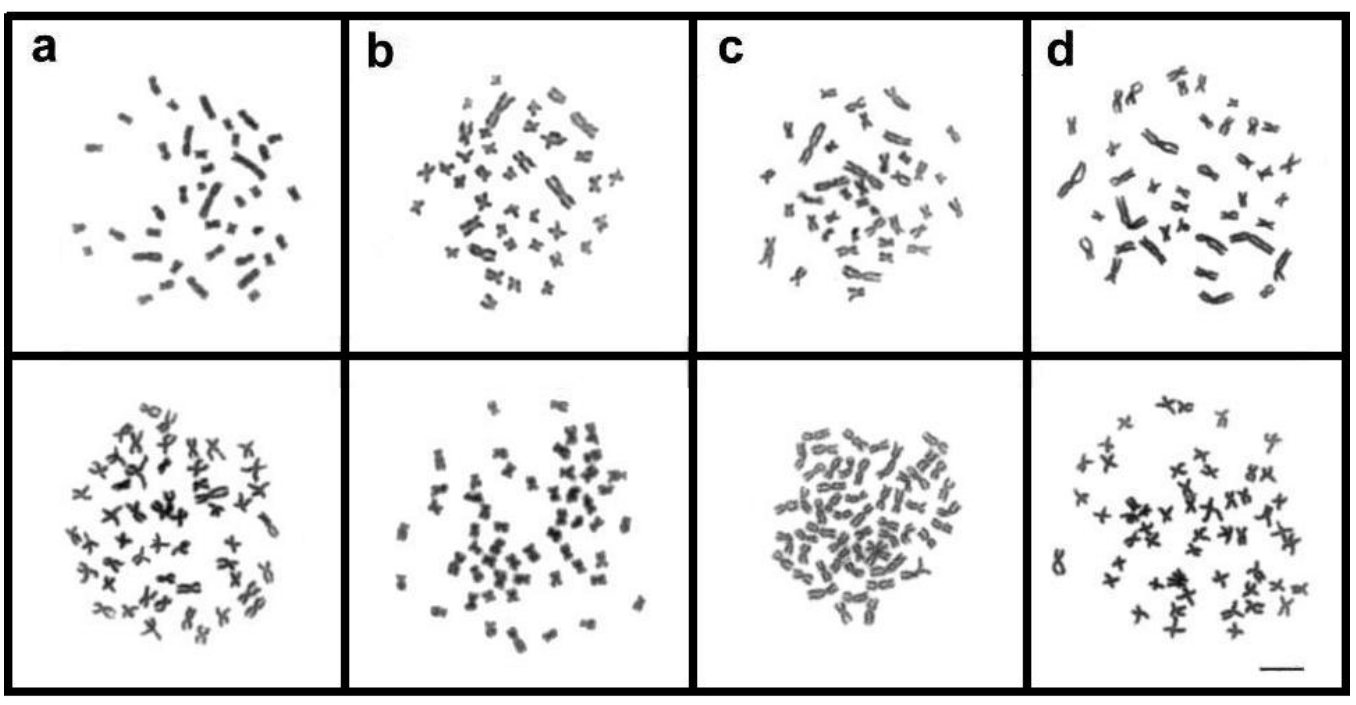

Figure 2. Mitotic metaphases of Hoplias malabaricus (above the horizontal line) and Prochilodus brevis (below the horizontal line) obtained after induction with (a) Aminovac ${ }^{\circledR}$ (T2), (b) Broncho-Vaxom ${ }^{\circledR}$ (T3), (c) Estimoral ${ }^{\circledR}$, and (d) Saccharomyces cerevisae. Bar $=5 \mu \mathrm{m}$. 


\section{DISCUSSION}

Comparative analyses between the treatments showed that the compounds Aminovac ${ }^{\circledR}$ (T2), Broncho-Vaxom ${ }^{\circledR}$ (T3) and Estimoral ${ }^{\circledR}$ (T4) could efficiently stimulate mitosis in both fish species. The increased efficiency was due either to the increased number of metaphase spreads or to the lack of mortality caused by the immunostimulants.

These compounds proved to be suitable activators of cell proliferation coupled with less aggressive effects in contrast to those of yeast inoculation, particularly mortality. Similar results have been reported for the immunostimulant Munolan ${ }^{\circledR}$ (Molina, 2001). Among the treatments performed herein, Aminovac ${ }^{\circledR}$ (T2), which comprises antigen complexes from food, air and bacteria, resulted in a 5-fold higher number of metaphases compared to the control group.

Several studies have focused on the development of vaccines to provide resistance to fish diseases in captive animals (Pakingking Jr. et al., 2009); indirectly, the knowledge from these studies has provided insight into the (usually unclear) mechanisms involved in the fish immunological response. Certain immunostimulants can trigger non-specific defense pathways, thereby preventing infectious diseases. The efficacy of some of these compounds has been determined under different inoculation procedures (Sakai et al., 2001) and, in some cases, they have resulted in a remarkable increase in the phagocytic activity of leukocytes in the kidney.

One of the most commonly used methods for mitotic induction in fish cytogenetics utilizes intramuscular or intraperitoneal inoculation with a solution of live yeast cells obtained from a 24- to 56-h culture of S. cerevisae (Cavallini and Bertollo, 1988). This method generally provides good results in several fish species, but it is potentially injurious to the animals and may lead to a significant mortality rate dependent on both the inoculation ability and physiological state of the specimen.

After intraperitoneal inoculation, some bacteria have been shown to release toxic extracellular enzymes such as hemolysin, protease, lipase, amylase, and phospholipase (Romalde and Toranzo, 1993). In general, vaccines using live organisms result in a more marked cell response (Marsden et al., 1996). Thus, similar levels of biological toxicity could be expected from the injection of live yeast cells into fish.

Studies based on the injection of live or sonicated bacteria in some fish species revealed no differences in immunological response between the two treatments (Zilberg and Munday, 2001), even though attenuated organisms yield a higher immune response than that of dead bacteria (Temprano et al., 2005).

The information obtained from the immunological response to vaccines in fish could also be used to evaluate the actual effects of these immunostimulating agents on the induction of dividing cells, which are the source of the metaphases needed for any cytogenetic study. Individuals that were not exposed to antigens generally present a low mitotic index in kidney cells, which hinders most chromosomal analyses in species with a low metabolism or in genotoxicity studies. Despite their importance, several of these stimulation methods have some disadvantages related to handling, expense or health risks to the researcher.

Complexes of bacterial and fungal antigens have proved to be remarkably efficient in fish with respect to both the increase in the number of mitotic cells and the lack of mortality; thus, they represent an alternative to the glucose solution of yeasts. This approach has been 
routinely tested on an array of fish species from several orders such as Perciformes (Sena and Molina, 2007), Anguilliformes (Vasconcelos and Molina, 2009), Beryciformes (Bacurau and Molina, 2004), and Characiformes (Medrado et al., 2008; Pamponet et al., 2008), among others.

Given that there are constant advances in the methodologies used in chromosomal analysis, and given that the chromosomal parameters of fish have been increasingly used as bioindicators, the ability to increase the number of dividing cells is mandatory in fish cytogenetic analyses. Techniques that involve great efforts both in terms of resources as well as preparation and analysis time, such as chromosomal mapping of DNA sequences, are significantly favored when a large number of metaphase spreads are available. Therefore, improvements in mitotic stimulation are a key step for a successful study. Given this approach, the present study demonstrated that the compounds used as activators of cell proliferation are adequate at the recommended dosages for fast $(24 \mathrm{~h})$ stimulation. The inoculations yielded both significant increases in the mitotic index, ranging from 7.44 (T4) to 12.22 (T2), and a higher performance, ranging from a 1.3- (T4) to 2.1-fold (T2) increase, when compared to the traditional yeast treatment (T5).

The commercial immunostimulants used in the present study increased the number of dividing defense cells and were demonstrated to be adequate for use in cytogenetic analyses related to evolutionary, taxonomic, population, or genotoxic studies, which depend on a large number of chromosomal counts. Therefore, these agents can be routinely used as an alternative to the conventional glucose-yeast solution for yielding metaphases. In some cases, however, the major advantage of this treatment method appears to be reduced sample loss, making the use of these agents particularly suitable for studies of specimens that have high commercial value or that are fragile, small and/or rare.

\section{ACKNOWLEDGMENTS}

Research supported by CNPq (\#556793/2009-9) and the Aquaculture Facility of DNOCS-Caicó, RN, Brazil, which provided the fish specimens used in this study. We thank José Veríssimo Fernandes (UFRN-DMP) for critical reviewing the manuscript and suggestions.

\section{REFERENCES}

Bacurau TOF and Molina WF (2004). Karyotypic diversification in two Atlantic species of Holocentridae (Pisces, Beryciformes). Caryologia 57: 300-304.

Baruffaldi A, Lanzara V and Cucchi C (1992). Utilization of phytohaemagglutinin for in vivo karyological studies in teleost fish. Cytobios 70: 49-52.

Cavallini MM and Bertollo LAC (1988). Indução de Mitoses em Hoplias malabaricus (Teleostei, Characiformes, Erythrinidae). Proceedings of the II Simpósio de Citogenética Evolutiva e Aplicada a Peixes Neotropicais, Maringá.

Cucchi C and Baruffaldi A (1989). A simple in vivo method for increasing mitoses in teleost fish. Cytobios 60: 165-169.

Cucchi C and Baruffaldi A (1990). A new method for karyological studies in teleost fishes. J. Fish Biol. 37: 71-75.

Gold JR, Li YC, Shipley NS and Powers PK (1990). Improved methods for working with fish chromosomes with a review of metaphase chromosome banding. J. Fish Biol. 37: 563-575.

Henyey E, Kynard B and Zhuang P (2002). Use of electronarcosis to immobilize juvenile lake and shortnose sturgeons for handling and the effects on their behavior. J. Appl. Ichthyol. 18: 502-504.

Kunz IW (2004). Developmental Biology of Teleost Fishes. Kluwer Academic Publishers Group, New York.

Lee MR and Elder FF (1980). Yeast stimulation of bone marrow mitosis for cytogenetic investigations. Cytogenet. Cell Genet. 26: 36-40.

Lozano R, Ruiz Rejon C and Ruiz Rejon M (1988). A method for increasing the number of mitoses available for cytogenetic 
analysis in rainbow trout. Stain Technol. 63: 335-338.

Marsden MJ, Vaughan LM, Foster TJ and Secombes CJ (1996). A live (delta aroA) Aeromonas salmonicida vaccine for furunculosis preferentially stimulates T-cell responses relative to B-cell responses in rainbow trout (Oncorhynchus mykiss). Infect. Immun. 64: 3863-3869.

Medrado AS, Figueiredo AVA, Waldschmidt AM, Affonso PRAM, et al. (2008). Cytogenetic and morphological diversity in populations of Astyanax fasciatus (Teleostei, Characidae) from Brazilian northeastern river basins. Genet. Mol. Biol. 31: 208-214.

Molina WF (2001). An alternative method of mitotic stimulation in fish cytogenetics. Chrom. Sci. 5: 149-152.

Molina WF (2007). Chromosome Changes and Stasis in Marine Fish Groups. In: Fish Cytogenetics (Pisano E, OzoufCostaz C, Foresti F and Kapoor BG, eds.). Science Publisher, Enfield, 69-110.

Moreira-Filho O and Bertollo LAC (1991). Astyanax scabripinnis (Pisces, Characidae): a species complex. Rev. Bras. Genet. 14: 331-357.

Ojima Y and Kurishita A (1980). A new method to increase the number of cells in the kidney tissue for fish chromosome studies mitotic. Proc. Japan Acad. Ser. B 56: 610-615.

Oliveira C, Almeida-Toledo LF and Foresti F (2007). Karyotype Evolution in Neotropical Fishes. In: Fish Cytogenetics (Pisano E, Ozouf-Costaz C, Foresti F and Kapoor BG, eds.). Science Publisher, Enfield, 111-164.

Pakingking R Jr, Seron R, dela Peça L, Mori K, et al. (2009). Immune responses of Asian sea bass, Lates calcarifer Bloch, against an inactivated betanodavirus vaccine. J. Fish Dis. 32: 457-463.

Pamponet VCC, Carneiro PLS, Affonso PRAM, Miranda VS, et al. (2008). A multi-approach analysis of the genetic diversity in populations of Astyanax aff. bimaculatus Linnaeus, 1758 (Teleostei: Characidae) from Northeastern Brazil. Neotrop. Ichthyol. 6: 621-630.

Park IS, Kim EM, Hur JW and Kartavtseva IV (2005). Yeast stimulation of bone marrow mitosis in the soft-shelled turtle, Pelodiscus sinensis crother for cytogenetic investigations. Korean J. Genet. 27: 141-144.

Ráb P, Bohlen J, Ràbová M, Faljshans M, et al. (2007). Cytogenetics as a Tool in Fish Conservation: The Present Situation in Europe. In: Fish Cytogenetics (Pisano E, Ozouf-Costaz C, Foresti F and Kapoor BG, eds.). Science Publisher, Enfield, 215-240.

Romalde JL and Toranzo AE (1993). Pathological activities of Yersinia ruckeri, the enteric redmouth (ERM) bacterium. FEMS Microbiol. Lett. 112: 291-299.

Sakai M, Taniguchi K, Mamoto K, Ogawa H, et al. (2001). Immunostimulant effects of nucleotide isolated from yeast RNA on carp, Cyprinus carpio L. J. Fish Dis. 24: 433-438.

Sena DC and Molina WF (2007). Robertsonian rearrangements and pericentric inversions in Scaridae fish (Perciformes). Genet. Mol. Res. 6: 575-580.

Takai A and Ojima Y (1995). Chromosome evolution associated with Robertsonian rearrangements in Pomacentrid fish (Perciformes). Cytobios 84: 103-110.

Temprano A, Riano J, Yugueros J, Gonzalez P, et al. (2005). Potential use of a Yersinia ruckeri O1 auxotrophic aroA mutant as a live attenuated vaccine. J. Fish Dis. 28: 419-427.

Vasconcelos AJM and Molina WF (2009). Cytogenetical studies in five Atlantic Anguilliformes fishes. Genet. Mol. Biol. 32: $83-90$.

Woznicki P, Jankun M and Wisniiewska AM (2004). A new in vivo method for increasing the mitotic index for teleost fish. Caryologia 57: 259-261.

Zilberg D and Munday BL (2001). Responses of Atlantic salmon, Salmo salar L., to Paramoeba antigens administered by a variety of routes. J. Fish Dis. 24: 183 . 